\title{
Study on the prevention of cross-infection by aerosols during scaling.
}

\author{
Jung-Ok Choi ${ }^{1}$, Yu-Jin Choi ${ }^{1}$, Seoul-Hee Nam ${ }^{2 *}$ \\ ${ }^{1}$ Department of Dental Hygiene, Youngsan University, Yangsan, Republic of Korea \\ ${ }^{2}$ Department of Dental Hygiene, College of Health Science, Kangwon National University, Samcheok-si, Republic of \\ Korea
}

\begin{abstract}
The purpose of this study was to prevent cross-contamination of dental hygienists by aerosols. We performed prophylactic scaling on 30 patients who visited the dental clinic. Microbiologic identification and SEM imaging were performed to confirm the number of microorganisms in the aerosol. Data analysis showed significant difference between two groups using SPSS (ver.21). According to the results, it was confirmed that Gram-positive and Gram-negative microorganisms were present in the aerosol, and these microorganisms were identified as microbes causing opportunistic infection in human body. In addition, chlorhexidine gargles were reduced to a significant level to reduce the number of microorganisms in the aerosol. A dental hygienist is likely to stay in a clinic room for a long time and be exposed to the generated aerosols. In order to prevent this, dental hygienists must thoroughly implement protection through personal protective equipment such as face shields and mask. In addition, reducing the number of microorganisms in the patient's mouth can be used gargling agents. In conclusion, the risks of cross-infection will be reduced through these methods.
\end{abstract}

Keywords: Aerosol, Cross-infection, Face shield, Prevention, Scaling.

Accepted on September 17, 2018

\section{Introduction}

With the various medical information provided through mass media, people have become concerned about infectious diseases and have developed an interest in their prevention and treatment, and their expectation of and demand for their own safety are increasing [1]. In particular, people's interest in nosocomial infections is on the rise. As such, optimal infection control efforts are being attempted to prevent nosocomial infections, and the responsibility and role of medical institutions for nosocomial infection control have been greatly emphasized.

In particular, dental treatment rooms are always exposed to a wide range of pathogenic microorganisms due to their nature. That is, secretions such as oral bacteria, saliva, and blood are spread to the air by hand pieces and ultrasonic scalers, which are frequently used for treatment, in the form of aerosols and droplets containing pathogenic microorganisms. Therefore, dental clinics pose a higher risk of infection compared to other medical institutions [2], and if the treatment room is contaminated, it can be a cross-infection-mediating site [3]. Spray droplets less than $5 \mu \mathrm{m}$ in size remain in the air, and if a person is not adequately protected, the possibility of such droplets' contact with the person's lungs is very high [4].

Therefore, infection control in dental treatment rooms is essential, and prevention of infection has been considered an important issue. For this reason, various methods have been sought to protect both the patients and dental employees from infection, and to prevent the spread of cross-infection between them through various routes, in the form of aerosols [5]. One of such methods is using protective equipment. Cross-infection can be prevented by wearing medical gloves, masks, safety goggles, face shields, and uniforms in the treatment room, which can reduce the number of microorganisms contacting the body [6].

To minimize the exposure to infection, it is necessary to acquire knowledge about the proper infection prevention measures, and to practice infection control. Infection control aims at preventing or reducing the incidence of infection among the patients and employees in medical institutions. It must be performed in a cost-effective way [7].

Infection control can be effective when the medical staff, patients, institutional managers, and infection managers all recognize its importance and practice it [8]. In particular, the role of dental hygienists, who frequently come in closest contact with the patients in the dental clinics, is very important. Despite this, however, there have been few studies on effective infection control through personal protection, one of the infection control methods used by dental hygienists in clinical practice. Moreover, the standards of the infection control index, which can serve as criteria for clinical application, have not yet been completely prepared for infection control in dental 
medical institutions, despite the high risk of exposure to infection therein.

This study aimed to reduce the risk of infection in dental treatment rooms through the airborne bacteria from aerosols during scaling, by promoting the use of face shields and prophylactic antimicrobial agents, and ultimately, to improve the quality of the medical services provided.

\section{Materials and Methods}

\section{Sample collection}

A total of 30 patients were treated with prophylactic scaling. During the procedure, the dental hygienist was required to wear a face shield and to generate aerosol on its surface. To confirm the reduction of the bacteria in aerosols by $0.1 \%$ chlorhexidine solution, the experimental subjects were divided into two groups. The first experimental group did not gargle with chlorhexidine before the prophylactic scaling while the second gargled with chlorhexidine for $30 \mathrm{~s}$.

To confirm the strain and number of bacteria present in the samples, the front part of the face shield was uniformly rubbed with a sterilized cotton swab at $5 \times 5 \mathrm{~cm}$, as shown in Figure 1 . Then the swab samples were placed in $3 \mathrm{~mL}$ sterile distilled water and were stored at $4^{\circ} \mathrm{C}$.

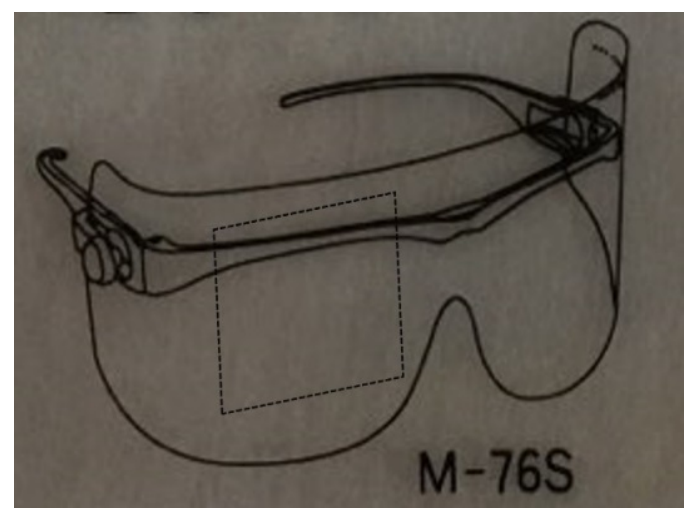

Figure 1. Microbial collection of face shield $(5 \times 5 \mathrm{~mm})$.

\section{Identification of bacteria and confirmation of the presence of colony-forming units (CFUs)}

To measure the number of bacteria on the surface of the face shield, $100 \mu \mathrm{L}$ of each collected sample was dispensed in the LB medium, spread evenly with a sterilized glass rod, and incubated at $36^{\circ} \mathrm{C}$ for $48 \mathrm{~h}$. After incubation, the viable cell count at the CFU was obtained with the naked eyes and was expressed at the CFU. For identification analysis, the samples were isolated into pure culture with the streak plate culture technique, and were incubated. The gene extraction was carried out by boiling lysis method and PCR was performed using universal primers $27 \mathrm{~F}$ and $1492 \mathrm{R}$ to amplify bacterial $16 \mathrm{~S}$ rDNA and the amplified PCR products were electrophoresed to analyse the $16 \mathrm{~S}$ rDNA sequence. Through this process, the species names are shown in Table 1.

\section{Scanning electron microscopy (SEM) preparation}

To compare the numbers of bacteria in the two experimental groups (with and without chlorhexidine gargling), SEM (S3500N, Hitachi Co., Japan) analysis was performed. The front part of the face shield was dried via pre-treatment, was plated with platinum, and was magnified at an accelerating voltage of $15 \mathrm{kV}$ for observation.

\section{Statistical analysis}

The CFU data were analysed using SPSS (version 21.0). The mean and standard deviation of the CFUs were calculated, and t-test analysis was performed to identify the difference according to chlorhexidine use or non-use.

\section{Results}

\section{Identification of the bacteria collected from the face shield}

As a result of the PCR on the samples collected from the face shield, two kinds of strains were identified. The gram-positive strain was identified as Micrococcus luteus, and the gramnegative strain, Moraxella osloensis (Table 1).

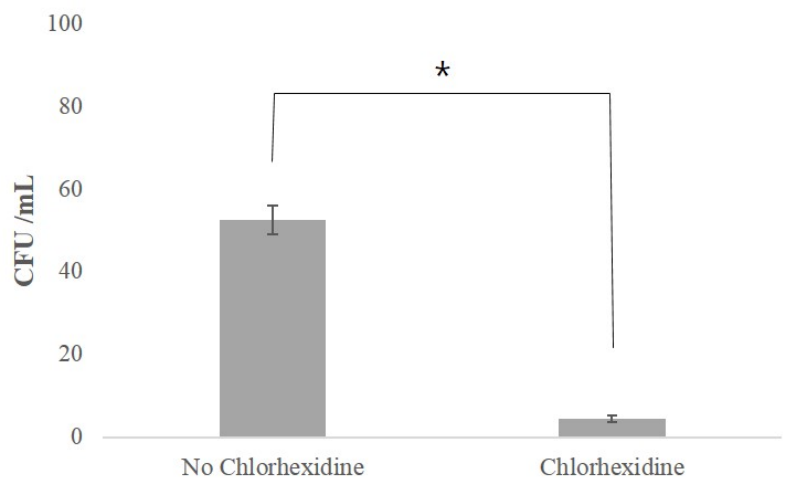

Figure 2. Microbial count with gargling between two groups.
(A)

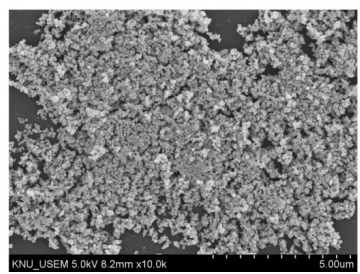

(B)

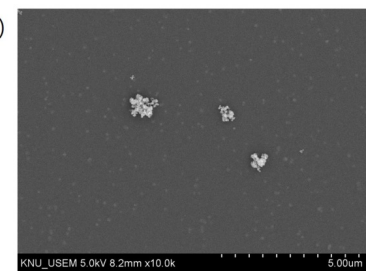

Figure 3. Changes in the number of surface microorganisms according to the presence or absence of chlorhexidine with $10000 \mathrm{X}$ magnification (A) No chlorhexidine (B) Chlorhexidine application.

\section{CFUs collected from the face shield}

Table 2 shows the result of gargling with chlorhexidine, a parameter affecting the airborne viable particulate count by aerosols. Through the observation of the face shield via SEM, it was found that there was a significant difference in the number of bacteria between the two experimental groups (with and without chlorhexidine gargling). In the group without any 
Study on the prevention of cross-infection by aerosols during scaling.

treatment before scaling, the average number of bacteria was 52.5 CFU/ml (Figure 2), but in the group where chlorhexidine gargling was applied, the average number of bacteria was 4.6 $\mathrm{CFU} / \mathrm{ml}$, which was remarkably small (Figure 3).

Table 1. Identification result of face shield surface microorganism.

\begin{tabular}{llll}
\hline Family & Species & Type & Primer sequence (5‘-3‘) \\
\hline Micrococcuaceae & Micrococcus luteus & Gram-positive & GGA TTA GAT ACC CTG GTA \\
\cline { 2 - 3 } & & CCG TCA ATT CMT TTR AGT TT \\
\hline Moraxellaceae & Moraxella osloensis & Gram-negative & CCG TCA ATT CMT TTR AGT TT \\
\cline { 2 - 3 } & & &
\end{tabular}

Table 2. The number of microorganisms according to the presence or absence of chlorhexidine.

\begin{tabular}{llll}
\hline Group & Number of face shield & CFU (Mean \pm SD) & P-value \\
\hline No chlorhexidine & 15 & $52.50 \pm 4.95$ & $0.000^{* *}$ \\
\hline Chlorhexidine & 15 & $4.60 \pm 0.89$ & \\
\hline
\end{tabular}

${ }^{*} p<0.05,{ }^{* *} p<0.01$

\section{Discussion}

This study was conducted to investigate the combined protection method against cross-infection and to help dental hygienists recognize the seriousness of cross-infection, which causes various diseases, so that they would take the initiative to wear personal protective equipment.

The aerosols generated in the dental treatment room contain various bacteria, causing air pollution in the room, which is a major part of the indoor pollution in the hospital. Nosocomial infection has been reported to be proportional to the degree of air pollution existing in the hospital [9]. In this study, Micrococcus luteus and Moraxella osloensis were identified among the gram-positive and gram-negative bacteria, respectively. Micrococcus luteus is resident oral flora, which is medically known as the endocarditis-inducing bacterium of the prosthetic heart valve [10,11]. Moraxella osloensis, on the other hand, is known to be a major causative bacterium of respiratory tract infection, and has been reported to show penicillin resistance [12]. Previous studies have also suggested that dental employees should consider the risk of infection as they are frequently exposed to bioaerosols [13,14]. For the prevention of infectious diseases, it is efficient to prevent exposure to infection or to prevent contamination by an infection medium, and direct contact with bacteria should be avoided. Considering that bioaerosols affect dental hygienists mainly through the respiratory system and skin, wearing a mask and a face shield seems essential for them.

Next, a way of reducing the bioaerosols by controlling the number of bacteria in the mouth can be chosen. Prophylactic scaling is usually performed with an ultrasonic scaler, which operates by causing the tip to vibrate with a sound wave using a liquid medium. Such liquid medium causes the release of aerosols containing the patient's blood and saliva, which may contain bacteria [15]. In particular, ultrasonic scalers have been reported to generate more aerosols than hand pieces and airwater syringes [16]. For this reason, it has also been reported that the use of an ultrasonic scaler is associated with an increase in the prevalence of respiratory disease in dental medical staff [17]. Allosopp et al. [18] reported that a high rate of eye and skin hypersensitivity or infection was shown in dental employees who used an ultrasonic scaler for more than $60 \mathrm{~min}$ a day.

Chlorhexidine is widely used as an antimicrobial agent for the mouth. It is absorbed by the surface of the mouth and is slowly released over a long period of time $[19,20]$. In addition, it exhibits a wide range of antimicrobial activities against grampositive bacteria, gram-negative bacteria, and various infectious viruses [21]. The chlorhexidine used in this study showed an approximately $88 \%$ reduction effect on the number of bacteria in aerosols when applied before scaling. In fact, the effect of chlorhexidine on the reduction of the number of bacteria has been revealed in many studies [22,23]. In light of these results, gargling with chlorhexidine before scaling seems to be essential for preventing cross-infection.

This study has limitations as a cross-sectional experimental study. First, the results were drawn with the one-time sampling of aerosols. Thus, the settings for aerosol control in which various parameters are applied will be needed. Second, the infection risk analysis was not sufficient because the possibility of infection of the respiratory system through the mask and face shield was not considered.

\section{Conclusion}

In this study, the number of bacteria contained in aerosols generated during prophylactic scaling using an ultrasonic scaler was effectively reduced by requiring the dental hygienists to wear a face shield, personal protective equipment for preventing contact with bacteria, and by requiring the patients to gargle with chlorhexidine before the treatment.

\section{Acknowledgments}

This work was supported by Youngsan University Research Fund of 2018. 


\section{Conflict of Interest}

The authors report no conflicts of interest related to this study. The author does not have any financial interest in the companies whose materials are included in the article.

\section{References}

1. Lee YA, Jo MJ, Bae JY, Park HS. A study on practice of infection control among dental staffs in dental office. J Dent Hyg Sci 2007; 7: 263-269.

2. Hardie J. Concerns regarding infection control recommendations for dental practice. J Can Dent Assoc 1922; 58: 337-386.

3. Thomson WM, Stewart JF, Carter KD, Spencer AJ. Public perception of cross-infection control in dentistry. Aust Dent J 1997; 42: 291-296.

4. Miller RL, Micik RE. Air pollution and its control in the dental office. Dent Clin North Am 1978; 22: 453-476.

5. Moon SE, Lee DD, Kwon HK, Kim KJ. Analysis of infection types on Stapylococcus aureus in dental office. J Korean Assoc Maxillofac Plast Reconsta Surg 2003; 25: 25-32.

6. Kim $\mathrm{CH}$, Jang HK. Investigation of infection prevention by dental hygienists personal protection. J Dent Hyg Sci 2005; 5: 63-70.

7. Scheckler WE, Brimhall D, Buck AS, Ferr BM, Friedman C, Garibaldi RA, Gross PA, Harris JA, Heirholzer WJ, Martone WJ, McDonald LL, Solomon SL. Requirements for infrastructure and essential activities of infection control and epidemiology in hospitals: A consensus panel report. AJIC 1998; 26: 47-60.

8. Choi DR, Kim SH. The study on organization, infection controller, patient infection control of dental clinic in certain areas. J Dent Hyg Sci 2015; 15: 399-406.

9. Kundsin RB. Documentation of airborne infection during surgery. Ann N Y Acad Sci 1980; 353: 255-261.

10. Seifert $H$, Kaltheuner $M$, Perdreau-Remington F. Micrococcus luteus endocarditis: case report and review of the literature. Zentralblatt für Bakteriologie 1995; 282: 431-435.

11. Miltiadous G, Elisaf M. Native valve endocarditis due to Micrococcus luteus: a case report and review of the literature. J Med Case Rep 2011; 5: 251.

12. Bae JH, Kim MN, Jung JS. Clinical microbiology for infection control. Hanmi Medical Book 2007.
13. Kadaifciler DG, Okten S, Sen B. Mycological contamination in dental unit waterlines in Istanbul, Turkey. Braz J Microbiol 2014; 44: 977-981.

14. Nejatidanesh F, Khosravi Z, Goroohi H, Badrian H, Savabi O. Risk of contamination of different areas of dentists face during dental practices. Int J Prev Med 2013; 4: 611-615.

15. Son WK, Shin SY, Kye SB, Yang SM. The effect of chlorhexidine on reduction of viable organisms in aerosol produced by ultrasonic scaler. J Korean Acad Periodontol 2009; 39: 303-310.

16. Legnani P, Checchi L, Pelliccioni GA, DAchille C. Atmospheric contamination during dental procedures. Quintessence Int 1994; 25: 435-439.

17. Rosen S, Schmakel D, Schoener M. Incidence of respiratory disease in dental hygienists and dietitians. Clin Prev Dent 1985; 7: 24-25.

18. Allsopp J, Basu MK, Browne RM, Burge PS, Matthews JB. Survey of the use of personal protective equipment and prevalence of work related symptoms among dental staff. Occup Environ Med 1997; 54: 125-134.

19. Schiott CR, Loe H, Jensen SB, Kilian M, Davies RM, Glavind K. The effect of chlorhexidine mouthrinses on the human oral flora. J Periodontal Res 1970; 5: 84-89.

20. Lang NP, Brecx MC. Chlorhexidine digluconate-an agent for chemical plaque control and prevention of gingival inflammation. J Periodont Res 1986; 21: 74-89.

21. Kolahi J, Soolari A. Rinsing with chlorhexidine gluconate solution after brushing and flossing teeth: a systematic review of effectiveness. Quintessence Int 2006; 37: 605-612.

22. Muir KF, Ross PW, MacPhee IT, Holbrook WP, Kowolik MJ. Reduction of microbial contamination from ultrasonic scalers. Br Dent J 1978; 145: 76-78.

23. Ciancio S. Expanded and future uses of mouthrinses. J Am Dent Assoc 1994; 125: 29-32.

\section{*Correspondence to}

Seoul-Hee Nam

Department of Dental Hygiene

College of Health Science

Kangwon National University

Republic of Korea 